Supporting Information

\title{
Removal of methylated arsenic in groundwater with iron filings
}

Cheng, Z.; Van Geen, A.; Louis R.; Nikolaidis, N.; Bailey, R.

Number of pages: 2 (excluding this cover page)

Number of tables: 1 
Table S.1. Simplified molecular structure and acidity constants of arsenate, arsenite, MMA and DMA.

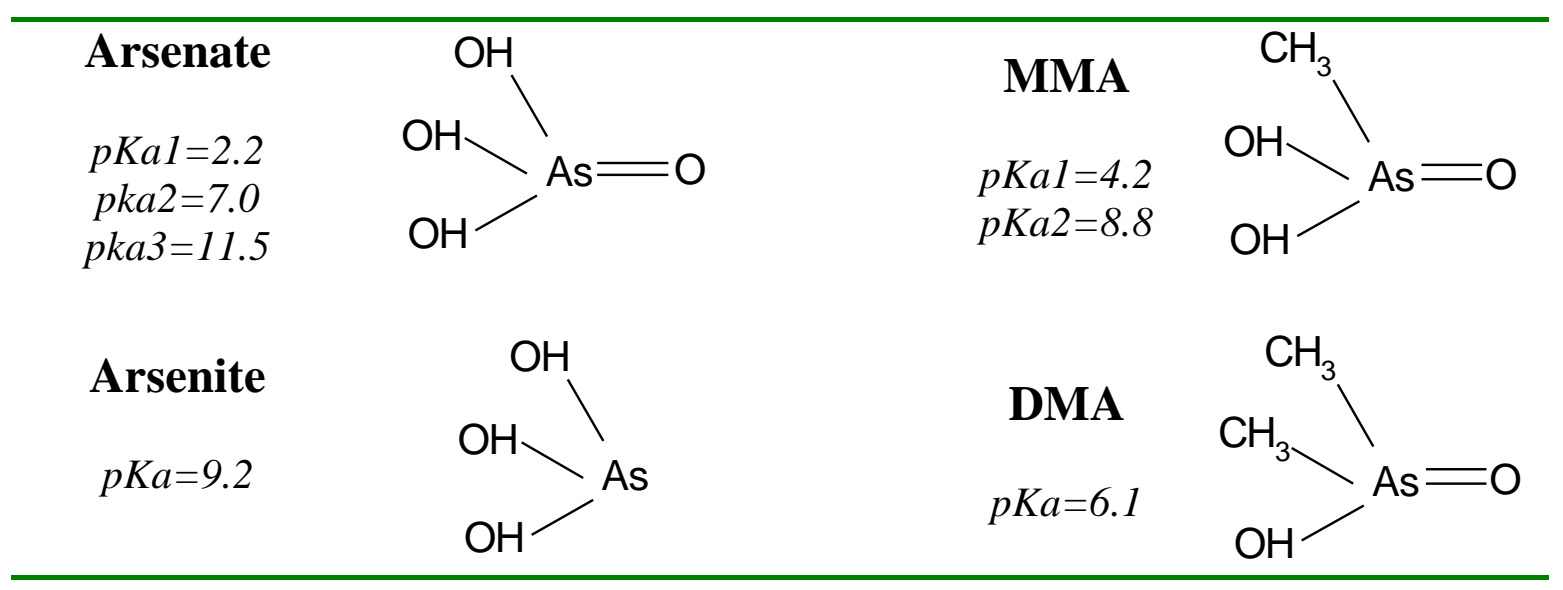




\section{Method Description: Arsenic speciation analyses using HPLC HR ICP-MS.}

Arsenic speciation was performed by ion chromatography. The system was comprised of a Dionex HPLC pump, a PRP X-100 (Hamilton, 250mm x $4.1 \mathrm{~mm}$ i.d., $10 \mu \mathrm{m}$ particle size) separation column, and a guard column with the same packing material connected between the injector and the separation column. The mobile phase at a flow rate of 0.8 $\mathrm{mL} / \mathrm{min}$ was $10 \mathrm{mM} \mathrm{NH} \mathrm{H}_{2} \mathrm{PO}_{4}$ with $\mathrm{pH}$ adjusted to 7.6. A 3-way splitter was used to reduce the flow into the nebulizer to $0.2 \mathrm{~mL} / \mathrm{min}$. Arsenic species were detected by online HR ICP-MS (Axiom Single Collector, Thermo Elemental). 